\title{
0 ensino de Geometria com parlendas: uma ação formativa
}

\author{
Edvonete Souza de Alencar \\ Aldrin Cleyde da Cunha \\ Janielle da Silva Melo da Cunha
}

\begin{abstract}
Resumo: Este artigo é resultado de uma formação continuada com professores, coordenador da instituição e alunos bolsistas do Programa Institucional de Bolsa de Iniciação à Docência (PIBID). As ações foram desenvolvidas no projeto do Laboratório Interdisciplinar de Formação de Educadores (LIFE) da Universidade Federal da Grande Dourados, em Mato Grosso do Sul, Brasil. Nosso objetivo foi o de promover a reflexão desse grupo formativo utilizando-se de recursos como: textos que se sabe de cor relacionando-os a atividades do conteúdo matemático, qual seja, Geometria. Evidenciamos assim a importância do uso de textos para o ensino interdisciplinar. A formação envolveu as seguintes atividades: embasamento teórico, apresentação de parlendas, dinâmica da parlenda cantada - brincadeira de pular corda, reflexão sobre que atividades podem ser realizadas, solicitação de representação por desenho da parlenda. Diante dessa formação, percebemos a necessidade de realizar ações formativas interdisciplinares e colaborativas, incentivando uma formação lúdica e prazerosa para o ensino de Geometria.
\end{abstract}

Palavras-chave: Educação Matemática. Formação de professores. Ensino e Aprendizagem. Geometria. Parlenda.

\section{The Geometry teaching with rhymes: the formative action}

Abstract: This article is the result of continuing education with teachers, the institution's coordinator, and scholarship students from the Institutional Program for Teaching Initiation Scholarships (PIBID). The actions were developed in the project of the Interdisciplinary Laboratory for the Training of Educators (LIFE) of the Federal University of Grande Dourados in Mato Grosso do Sul, Brazil. Our objective was to promote the reflection of this training group using resources such as: texts that are known by heart, relating them to activities of mathematical content, whatever, - Geometry. We thus highlight the importance of using texts for interdisciplinary teaching. The training developed the following activities: theoretical background, presentation of the rhymes, dynamics of the sung rhymes - skipping rope, reflection on what activities can be carried out, request for representation by drawing the rhymes. Given this formation, we realized the need to carry out interdisciplinary and collaborative training actions, encouraging a playful and enjoyable formation for the teaching of Geometry.

Keywords: Mathematics Education. Teacher training. Teaching and Learning. Geometry. Rhymes.
Edvonete Souza de Alencar Doutora em Educação Matemática. Professora da Faculdade de Educação da Universidade Federal de Grande Dourados (UFGD). Mato Grosso do Sul, Brasil. iD orcid.org/0000-0002-5813-8702

$\square$ edvonete.s.alencar@hotmail.com

Aldrin Cleyde da Cunha Doutor em Educação Matemática. Professor do Programa de Pós-Graduação em Educação e Territorialidade da Universidade Federal da Grande Dourados (UFGD). Mato Grosso do Sul, Brasil. iD orcid.org/0000-0002-0665-6436

$\triangle$ aldrincunha@ufgd.edu.br

Janielle da Silva Melo da Cunha

Doutorado em Biotecnologia e Biodiversidade. Professora da Universidade Federal do Amapá (UNIFAP). Amapá, Brasil. iD orcid.org/0000-0002-4473-0510 \janiellecunha@gmail.com

Recebido em 30/06/2020 Aceito em 15/10/2020 Publicado em 17/11/2020 


\section{Enseñanza de la Geometría con rimas: una acción formative}

Resumen: Este artículo es el resultado de la educación continua con maestros, el coordinador de la institución y los estudiantes becados del Programa Institucional para Becas de Iniciación Docente (PIBID). Las acciones se desarrollaron en el proyecto del Laboratorio Interdisciplinario para la Formación de Educadores (LIFE) de la Universidad Federal de Grande Dourados en Mato Grosso do Sul, Brasil. Nuestro objetivo fue promover la reflexión de este grupo de capacitación utilizando recursos tales como: textos que se conocen de memoria, relacionándolos con actividades de contenido matemático, lo que sea, Geometría. Por lo tanto, destacamos la importancia de utilizar de textos para la enseñanza interdisciplinaria. La capacitación desarrolló las siguientes actividades: antecedentes teóricos, presentación de las parlendas, dinámica de la parlenda cantada: saltar la cuerda, reflexión sobre qué actividades se pueden llevar a cabo, solicitud de representación dibujando la parlenda. Dada esa formación, nos dimos cuenta de la necesidad de llevar a cabo acciones de formación interdisciplinarias y colaborativas, fomentando una formación lúdica y agradable para la enseñanza de la Geometría.

Palabras clave: Educación Matemática. Formación de profesores. Enseñanza y Aprendizaje. Geometría. Rima.

\section{Introdução}

La na casa da vizinha Tem feijão na panelinha Tem biscoito com café

Para comer com o Zezé (EMIRENE, 2008, p. 20)

Este artigo apresenta uma ação formativa desenvolvida com um grupo de professores que lecionam para o $3^{\circ}$ ano do Ensino Fundamental em uma cidade do interior do Mato Grosso do Sul. Participou, também, o coordenador da Educação Básica da instituição pública parceira e alunos bolsistas do Programa Institucional de Bolsa de Iniciação à Docência (PIBID). Salientamos que, apesar da turma de professores lecionarem no $3^{\circ}$ ano, o que caracteriza a metade nos Anos Iniciais do Ensino Fundamental, desenvolvemos esta formação e a justificamos, pois as turmas de $3^{\circ}$ ano desta instituição estão com alunos em dificuldades de alfabetização linguística e matemática.

Consideramos, assim, que formações com diferentes abordagens e metodologias podem auxiliar no planejamento e desenvolvimento de atividades para alunos com dificuldades de aprendizagem. Essas ações formativas foram desenvolvidas no Laboratório Interdisciplinar de Formação de Educadores (LIFE) da Universidade Federal da Grande Dourados (UFGD), em Mato Grosso do Sul, Brasil, no período formativo de uma semana. O objetivo deste espaço, segundo 
dados da página oficial da universidade 1 , é "promover a interação entre os cursos de formação de professores, bem como desenvolver atividades de caráter interdisciplinar envolvendo os professores e acadêmicos das licenciaturas e rede pública de ensino".

Nosso objetivo neste artigo foi o de promover a reflexão desse grupo formativo, permitindo que reconhecesse a necessidade de utilizar meios significativos para os alunos - textos que se sabe de cor, brincadeiras, poesias , músicas e outros - para o planejamento de suas ações pedagógicas, visando uma maior relação entre o vivido pelo 0 aluno e o conhecimento escolar. Especificamente, apresentamos um excerto da ação formativa apresentando como as parlendas podem ser utilizadas para o ensino de Geometria. Relataremos mais sobre as especificidades abordadas na seção posterior.

A parlenda de autoria de Emirene (2008), reflete o cenário infantil e nos permite estabelecer relações com "textos que se sabe de cor"2 usados no cotidiano para o ensino das diferentes disciplinas, entre elas, a Matemática. A utilização de textos que possuem rima como músicas, parlendas, poemas e outros são importantes para a percepção dos sons pelos alunos. Essa percepção auxilia nas atividades de Letramento Linguístico e Matemático.

Assim, ao elaborarmos um plano de ação formativo que trabalhasse com as parlendas, evidenciamos estabelecer relações do cotidiano infantil com as diferentes disciplinas. Os trabalhos com esses tipos de textos são importantes, pois estão presentes nas brincadeiras infantis, possuem fácil compreensão e desenvolvem a capacidade de memória (BJORKLUND, 2017). Acreditamos que propiciar momentos de reflexão com atividades diferentes ao que comumente é proposto nas formações pode ser benéfico para o desenvolvimento de ações pedagógicas mais eficientes para a aprendizagem dos alunos.

Assim, organizamos este artigo apresentando considerações sobre o uso de parlendas para o ensino de Matemática, as reflexões sobre as formações de professores, a ação formativa e algumas considerações.

\footnotetext{
1 https://portal.ufgd.edu.br/programa/life/index

2 São textos culturais, populares, que são memorizados e passados de geração para geração e que possuem rima (WEISZ, 1999).
} 


\title{
2 Parlendas: a importância dos textos que se sabem de cor para o ensino de Matemática
}

Em um vídeo ${ }^{3}$ organizado pela Secretaria de Ensino Fundamental do Ministério da Educação para um programa de formação de professores alfabetizadores, Telma Weisz e Rosaura Soligo nos explicam sobre como surgiu os textos que se sabem de cor, utilizando-se de dados do historiador Alberto Manguel em seu livro Uma história da leitura. Mencionam que os modos de leitura nas épocas antigas na Europa e na América eram as histórias orais, pois havia poucas pessoas que sabiam ler e nesta época era comum ter os momentos de roda de leitura, nos quais eram promovidas leituras orais de histórias e passagens bíblicas. Como eram poucos textos que as pessoas tinham acesso, as histórias eram lidas várias vezes e, por tanto, eram memorizadas e passavam de geração para geração.

Vemos assim, que esses tipos de texto tiveram sua importância e seu significado. Nos dias atuais, ele é utilizado em um contexto mais lúdico, no entanto ainda é muito usado para o desenvolvimento de percepções do mundo letrado. Weisz (1999) apresenta esse tipo textual em suas formações como um recurso importante para a alfabetização dos alunos. A autora, no documento formativo Programa de Formação de Professores Alfabetizadores, considera que

\begin{abstract}
os textos são os melhores aliados - não só porque garantem a não descaracterização do que é conteúdo da alfabetização, mas porque determinados tipos de texto favorecem a reflexão sobre as características da escrita alfabética. Quando as crianças ainda não lêem e não escrevem convencionalmente, a prática tem mostrado que alguns textos são bastante adequados para as situações de leitura e escrita: listas, canções, poesias, receitas, parlendas, provérbios, adivinhas, piadas, trava-língua, regras de instrução. Geralmente são textos curtos, em que os alunos têm possibilidades de antecipar o escrito (receitas conhecidas, regras de instruções, listas...), ou que sabem de cor (poesias, canções, provérbios, parlendas...). No caso dos textos poéticos, a organização em versos, a presença de rimas e os ritmos que animam cada um deles colaboram para que as crianças, embora não saibam ler no sentido convencional, possam ler esses textos. (BRASIL, 2001, p. 3).
\end{abstract}

É sabido que os textos que se sabem de cor sempre foram considerados importantes para o ensino de Língua Portuguesa, mas pesquisas recentes de Bjorklund (2017) têm indicado que a utilização de rimas nas aulas de Matemática colabora com a construção do sistema de numeração decimal.

O conceito de número é complexo e as pesquisas mostram que muitas competências parecem ser necessárias para as crianças, para desenvolver seu raciocínio numérico e as habilidades aritméticas. As crianças de três anos, a maioria já sabe o início da sequência de contar palavras e são familiarizadas com rimas e com palavras de

\footnotetext{
3 Publicado em 2001, disponivel em https://www.youtube.com/watch?v=8gHoXYkdXmY.
} 
número mesmo no berçário. Desenvolver uma compreensão avançada de diferentes significados de número em diferentes contextos é, no entanto, um processo contínuo até cerca de oito anos de idade. (BJORKLUND, 2017, p. 2)

Para a autora, as atividades que envolvem rima para o ensino de Matemática são potencializadoras desde as menores idades e auxiliam na aprendizagem de alunos até os 8 anos. Considerando que nossos professores lecionam para a turma de $3^{\circ}$ ano que, em média as crianças possuem a referida idade, a rima faz com que 0 aluno perceba os sons iguais das terminações das palavras e esta percepção trabalha a igualdade. Igualdade essa que é mencionada nos estudos de Kamii (1995) como a prova de conservação do número.

O uso desse tipo textual ainda faz com que o aluno crie a percepção e relação das formas geométricas com o cotidiano, e desenvolva a lateralidade e os sentidos de localização. Tais afirmações também são corroboradas por Silva (2017), que menciona a rima como um auxiliar no ensino para o ensino de Matemática.

Assim, a Parlenda, como outros textos que se sabem de cor, é importante para o ensino de Matemática visto que trabalha de modo lúdico e ritmado, histórias culturais que permitem a relação com os objetos do cotidiano e os números.

\section{0 ensino de Geometria com parlendas}

Como já citado anteriormente, uma das primeiras relações que são evidenciadas do uso de parlendas para o ensino de Geometria é a sua relação com os aspectos do cotidiano. Lima e Carvalho (2011) mencionam que nos primeiros anos de vida as crianças, ao engatinharem, já realizam o conhecimento dos objetos do espaço, com o desenvolvimento das habilidades motoras e cognitivas e, assim, vão desenvolvendo as competências geométricas, com a localização, com o reconhecimento dos deslocamentos, com a representação dos objetos do mundo físico, com a classificação das figuras e a sistematização dos conhecimentos neste campo.

Os autores nos dizem ainda que, historicamente, a Geometria sempre esteve em destaque desde as primeiras fases de desenvolvimento matemático, visto que várias civilizações antigas continham um grande conhecimento geométrico e aplicava esses conhecimentos em suas construções e atividades diárias.

Portanto, ao iniciar o estudo da Geometria com os alunos, os professores devem explorar as atividades que possibilitem a movimentação corporal, o manuseio e a visualização dos objetos 
no mundo físico. Deve, também, conter atividades que permitam a representação gráfica, como a elaboração de desenhos e imagens e estas serão utilizadas durante toda a formação do aluno em Geometria.

Assim, uma das considerações realizadas pelos autores é sobre a função da escola em potencializar ações para o desenvolvimento do pensamento geométrico. Indicam que esta é formado por duas capacidades; primeira é

\begin{abstract}
captar e interpretar as informações provenientes do mundo que nos cerca e que são mediadas pela visão humana, bem como constituir imagens mentais e ideias baseadas nessas informações. Por outro lado, traduzir as imagens mentais e as ideias em objetos visíveis. De forma simplificada, podemos dizer que a primeira é a capacidade de ver os objetos (físicos ou gráficos), o movimento e o espaço físico e de gerar imagens mentais. (LIMA e CARVALHO, 2010, p. 144)
\end{abstract}

E a segunda é "a de tornar visíveis nossas ideias e imagens mentais, por meio de objetos físicos ou de representações gráficas" (LIMA e CARVALHO, 2010, p. 144).

Consideramos, assim, que as parlendas como são textos ritmados, fazem parte do cotidiano infantil, proporcionam o desenvolvimento de atividades lúdicas, com as quais 0 aluno, ao brincar, também possa fazer relações espaciais, de percepção dos objetos existentes a sua volta que compõe a mensagem da parlenda, e que identifiquem as rimas existentes. A parlenda e as rimas existentes podem ser utilizadas como um recurso para estabelecer as relações entre 0 cotidiano infantil e o conhecimento matemático, no caso, a Geometria. Em nossa formação, apresentamos algumas das possibilidades em que o uso da parlenda pode ser benéfico para 0 ensino de conteúdos matemático.

Diante do exposto, consideramos adequado realizar a ação formativa promovendo essas relações e partindo de atividades que pudessem desenvolver o pensamento geométrico.

\title{
4 Algumas reflexões sobre a formação de professores
}

Quando mencionamos sobre uma formação de professores que considere os aspectos do cotidiano, a relação do cenário infantil e infanto juvenil e os conhecimentos necessários para 0 desenvolvimento da aprendizagem, temos que buscar refletir sobre quais investigadores propõem reflexões nesta vertente para a formação de professores. Assim, apresentamos os estudos de Carrillo-Yañez et al. (2018), que tratam sobre o Conhecimento Especializado de Professores de Matemática (Mathematics Teachers' Specialised Knowledge - MTSK). 
Este estudo apresenta, conforme Figura 1, o conhecimento do professor de Matemática em dois domínios e subdomínios, apresentando ainda as crenças e aspectos afetivos.

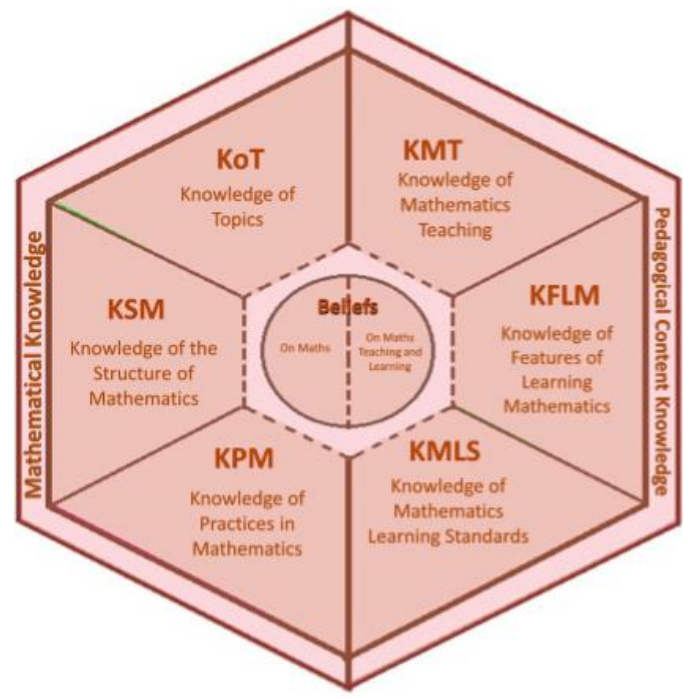

Figura 1: Modelo de Conhecimento Especializado do Professor de Matemática MTSK (Carrillo-Yañez et al., 2018, p. 271)

Identificamos na figura sua organização em dois grandes domínios: conhecimento matemático (MK) e conhecimento pedagógico do conteúdo (PCK).

O conhecimento matemático (MK) refere-se ao conhecimento do professor sobre as características e elementos da Matemática. Este domínio é composto pelos subdomínios: conhecimento dos tópicos (KOT), conhecimento da estrutura matemática (KSM) e 0 conhecimento da prática matemática (KPM).

O conhecimento didático do conteúdo (PCK) são os recursos utilizados para o ensino de Matemática; este é composto pelos subdomínios: conhecimento das características da Matemática de aprendizagem (KFLM), conhecimento do ensino de Matemática (KMT) e 0 conhecimento de padrões de aprendizagem da Matemática (KMLS).

Nesta seção ampliaremos mais informações sobre o conhecimento didático do conteúdo (PCK) e seus subdomínios, tendo em vista que nossas ações formativas têm como foco essas especificidades.

O conhecimento das características da Matemática de aprendizagem (KFLM) trata-se da percepção que os professores devem ter para entender como os alunos pensam para que possam auxiliá-lo em suas dificuldades e aprendizagens. Para isso, é importante que as formações iniciais e continuadas contenham embasamento teórico e prático que potencializem conhecer diferentes 
recursos e metodologias para o ensino. Em especial, neste subdomínio, há as teorias de aprendizagem, as relações dos alunos com o conhecimento e como refletem sobre os conteúdos. Além disso, esse subdomínio também abarca as influências das emoções das relações de ensino e aprendizagem.

O conhecimento do ensino de Matemática (KMT), refere-se ao potencial das atividades, as estratégias e metodologias de ensino. Assim abarca os recursos didáticos, as estratégias, as técnicas, tarefas e exemplos.

O conhecimento de padrões de aprendizagem da Matemática (KMLS) trata do conhecimento sobre os níveis de ensino que o aluno deve ter em um determinado segmento de ensino ou ano escolar. O professor deve saber as relações entre os conhecimentos anteriores e os próximos conteúdos a serem aprendidos. Esse subdomínio inclui os conhecimentos sobre os resultados esperados de aprendizagem, sequenciamento de tópicos e conhecimento curricular.

Cabe salientar ainda que todos os subdomínios possuem inter-relações para 0 desenvolvimento do ensino de da aprendizagem de Matemática.

\section{A ação formativa}

O grupo selecionado para o desenvolvimento da ação formativa, foi composto por participantes das atividades realizadas pelo Laboratório Interdisciplinar de Formação de Educadores (LIFE) da Universidade Federal da Grande Dourados (UFGD). Esse grupo é formado por escolas da educação básica, alunos bolsistas do Programa Institucional de Bolsa de Iniciação à Docência (PIBID) e pesquisadores da universidade. Em específico, nessa formação estava presente em uma das escolas com dificuldades na aprendizagem dos alunos do $3^{\circ}$ ano dos Anos Iniciais do Ensino Fundamental, em questão a alfabetização linguística e matemática.

A ação formativa foi planejada pensando em uma temática interdisciplinar que pudesse contribuir de modo significativo aos professores que atuam nessas turmas. Cabe salientar que pesquisas como Lozada et al. (2018), Masola e Allevato (2019) e Jalinek e Adam (2020) no faz refletir que nos últimos anos veem sendo incentivadas investigações para utilizar uma abordagem interdisciplinar tendo em vista os aspectos que alcancem uma melhor compreensão e aprendizagem. Por isso, selecionamos as parlendas mais conhecidas e que pudessem desencadear trabalhos com a sonorização e conhecimento do alfabeto, como também 0 
conhecimento geométrico e sua relação com as atividades do cotidiano, a relação com os aspectos artísticos, o trabalho com as diferentes moradias existentes e o movimento corporal ao pular corda. Propor o conhecimento de outras estratégias para ensinar Matemática em formação de professores desenvolve o conhecimento referentes à Matemática e aprendizagem (KFLM)

Inicialmente apresentamos a importância das parlendas para as atividades escolares, mostrando brevemente o embasamento teórico e pesquisas realizadas na área. 0 embasamento teórico apresentado foi desde os aspectos apontados pela Base Nacional Comum Curricular até os poucos embasamentos que há sobre as relações existentes entre os textos que se sabem de cor e o conhecimento matemático, tendo em vista que é um tema inovador e pouco explorado. Assim, estudamos um pouco sobre o papel das relações linguísticas e do uso das brincadeiras e suas influências no ensino de Matemática.

Depois, apresentamos três parlendas ao grupo, como pode ser vista no Quadro 1, realizamos a leitura cantada e iniciamos os preparativos para a dinâmica.

Quadro 1: Parlendas apresentadas na ação formativa

\begin{tabular}{|c|c|c|}
\hline Parlenda 1 & Parlenda 2 & Parlenda 3 \\
\hline $\begin{array}{c}\text { Suco gelado } \\
\text { Cabelo arrepiado } \\
\text { Qual é a letra } \\
\text { Do seu namorado? } \\
\text { A B CDEF G H I JKL M N O } \\
\text { PQRST U VXYZ }\end{array}$ & $\begin{array}{c}\text { Com quem você } \\
\text { Deseja casar? } \\
\text { Loiro, moreno } \\
\text { Soldado ou capitão } \\
\text { Qual a letra do seu coração? } \\
\text { A B C D E F G H I J KL M N O } \\
\text { P QR S T U V XYZ }\end{array}$ & $\begin{array}{c}\text { La na casa da vizinha } \\
\text { Tem feijão na panelinha } \\
\text { Tem biscoito com café } \\
\text { Para comer com o Zezé } \\
\text { Come Um } \\
\text { Come Dois } \\
\text { Come Três } \\
\text { Come Quatro } \\
\text { Come Cinco } \\
\text { Come Seis } \\
\text { Come Sete } \\
\text { Come Oito } \\
\text { Come Nove } \\
\text { Come Dez } \\
\text { Bata a porta } \\
\text { E o portão } \\
\text { E vá embora com seu cão }\end{array}$ \\
\hline
\end{tabular}

Fonte: SÃO PAULO (2014, p. 54 - Parlendas 1 e 2) e EMIRENE (2008, p. 20 — Parlenda 3)

A dinâmica da parlenda cantada foi realizada com a atividade de pular corda em ambiente 
ao ar livre. O grupo de professores foi levado à uma quadra e, em disposição de semicírculo, iniciamos a atividade. $O$ grupo foi cantando as parlendas e realizando a dinâmica. $A$ atividade permitiu que os professores se colocassem no lugar no aluno desempenhando suas atividades, reações e sentindo as emoções. Quando trabalhamos nas ações formativas com as relações que envolvem aprendizagem e sentimentos estamos desenvolvendo conhecimento sobre a Matemática e aprendizagem (KFLM). Além de ser um momento lúdico com o grupo, foi possível identificar a importância destes tipos de atividades para o desenvolvimento do pensamento geométrico como citado por Lima e Carvalho (2010), que mencionam sobre a importância da realização de atividades que contenham o movimento para a percepção de conceitos de lateralidade e da localização.

Descarte, no momento de reflexão com os professores foi possível perceber que movimentos com a dinâmica da parlenda cantada foram realizados para que pudéssemos identificar a Geometria. Foi citado por uma das alunas bolsistas que a corda precisa fazer movimentos circulares para que se possa realizar a brincadeira. Vemos com isso que a Geometria está presente nas ações do nosso cotidiano e, por isso, é um dos conteúdos matemáticos importantes para a formação do cidadão (LIMA e CARVALHO, 2010). Portanto, ter o conhecimento do ensino de Matemática (KMT) é um dos subdomínios essenciais para que o professor explore as diferentes estratégias e recursos de aprendizagem.

No momento de reflexão com o grupo foi possível explorarmos quais as atividades matemáticas poderiam ser realizadas utilizando a parlenda. Os professores, ao refletirem sobre quais atividades e conteúdos explorar, estão desenvolvendo o conhecimento de padrões de aprendizagem da Matemática (KMLS). As sugestões foram construídas de modo interdisciplinar, pois envolvem a arte, a escrita entre outras ações. Essas ações se referem ao conhecimento do ensino de Matemática (KMT). Assim, apareceram um conjunto de atividades que podem ser realizadas, como mostra o Quadro 2.

Quadro 2: Sugestões de atividades com parlenda

\begin{tabular}{|l|l|}
\hline Parlendas & \multicolumn{1}{|c|}{ Atividades } \\
\hline Parlenda 1 & $\begin{array}{l}\text { Quebra-cabeça sobre a parlenda } \\
\text { Colagem de figuras geométricas para a representação do cenário da } \\
\text { parlenda } \\
\text { Percepção das palavras que tem o mesmo som }\end{array}$ \\
\hline
\end{tabular}




\begin{tabular}{|l|l|}
\hline Parlenda 2 & $\begin{array}{l}\text { Quebra-cabeça com a parlenda } \\
\text { Utilização de dobradura para a representação da parlenda } \\
\text { Percepção das palavras que tem o mesmo som }\end{array}$ \\
\hline Parlenda 3 & $\begin{array}{l}\text { Trabalho com o sistema de numeração decimal } \\
\text { Representação do número - quantidade escrita dos números } \\
\text { Utilização da dobradura e das figuras geométricas para a sua } \\
\text { representação. }\end{array}$ \\
\hline
\end{tabular}

Fonte: Elaboração dos Autores

Após as reflexões iniciais foi solicitado que os professores realizassem um desenho utilizando das formas geométricas que representam a parlenda (Figura 3). Novamente, a atividade propõe ao professor para que se coloque no lugar no aluno vivenciando experiências que poderão levá-lo a refletir sobre suas práticas e ações pedagógicas.

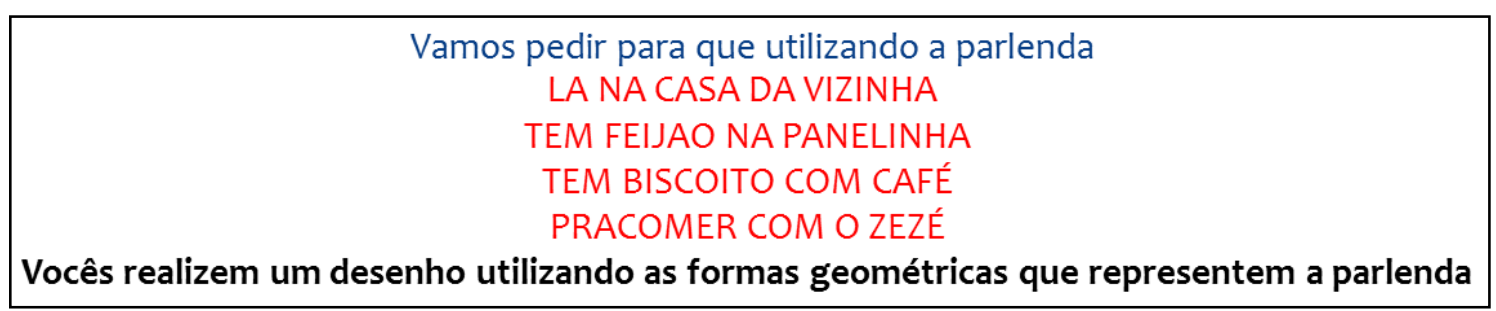

Figura 3: Solicitação da atividade realizada na formação (Elaboração dos Autores)

Foi dada uma folha de sulfite a cada um dos componentes do grupo e materiais coloridos como giz de cera e lápis de cor para que realizassem a atividade do mesmo modo que seria proposto aos alunos. Algumas das produções que obtivemos podem ser observadas nas Figuras 4,5 e 6.

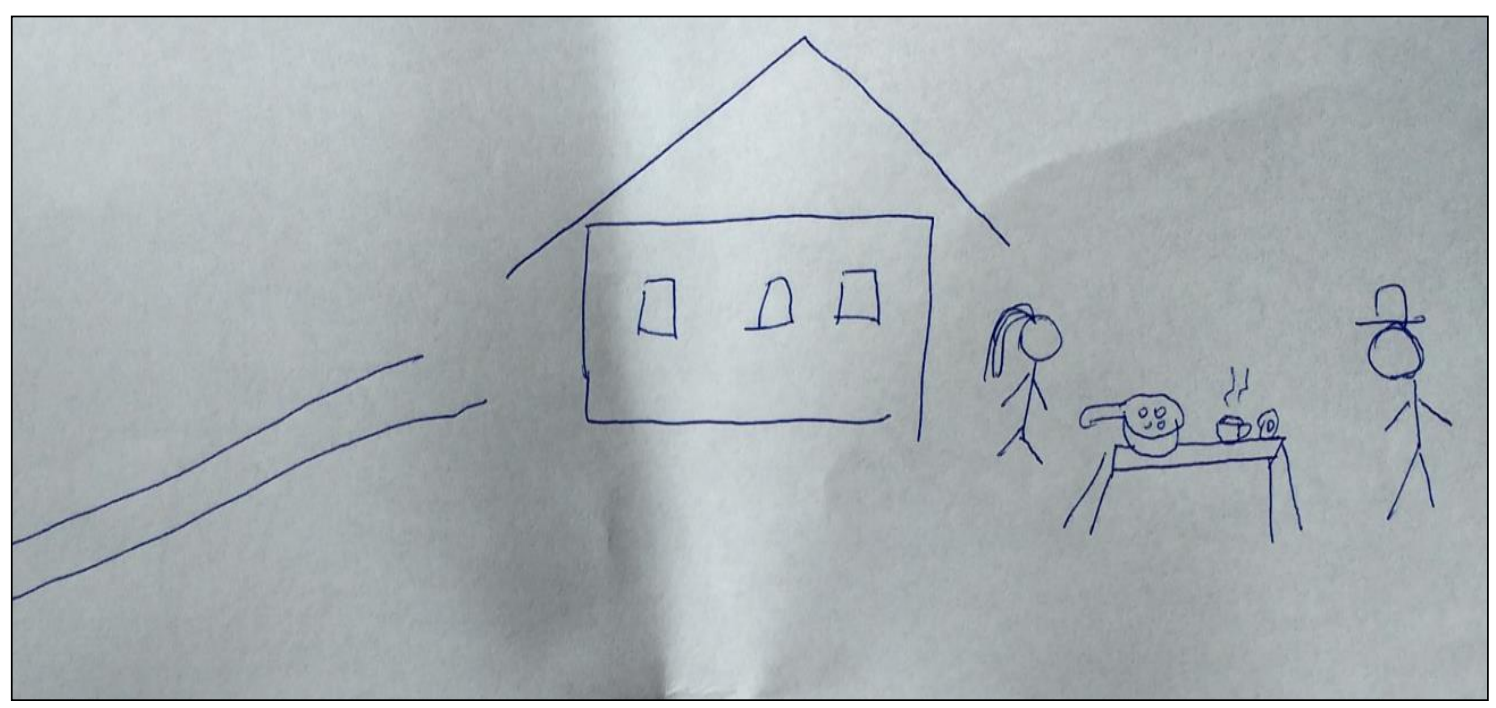

Figura 4: Registro do participante 1 (Dados da Pesquisa) 


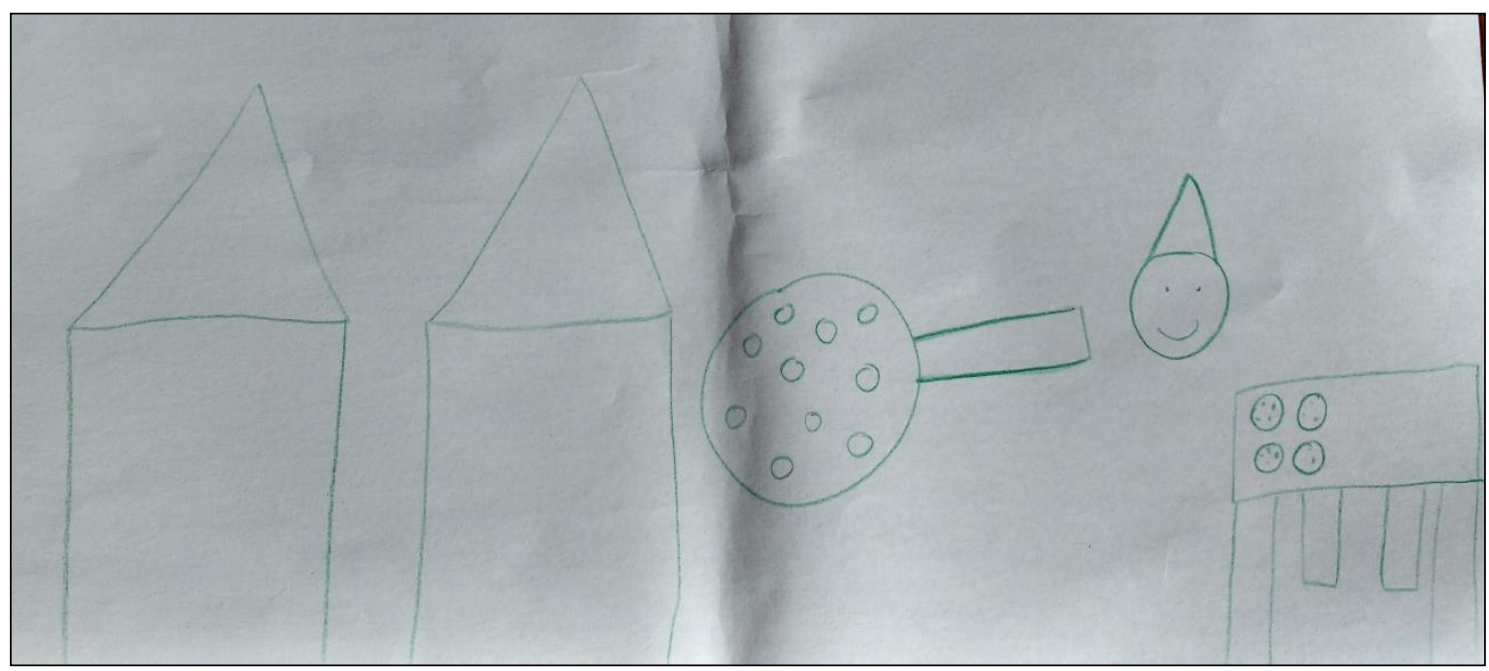

Figura 5: Registro do participante 3 (Dados da Pesquisa)

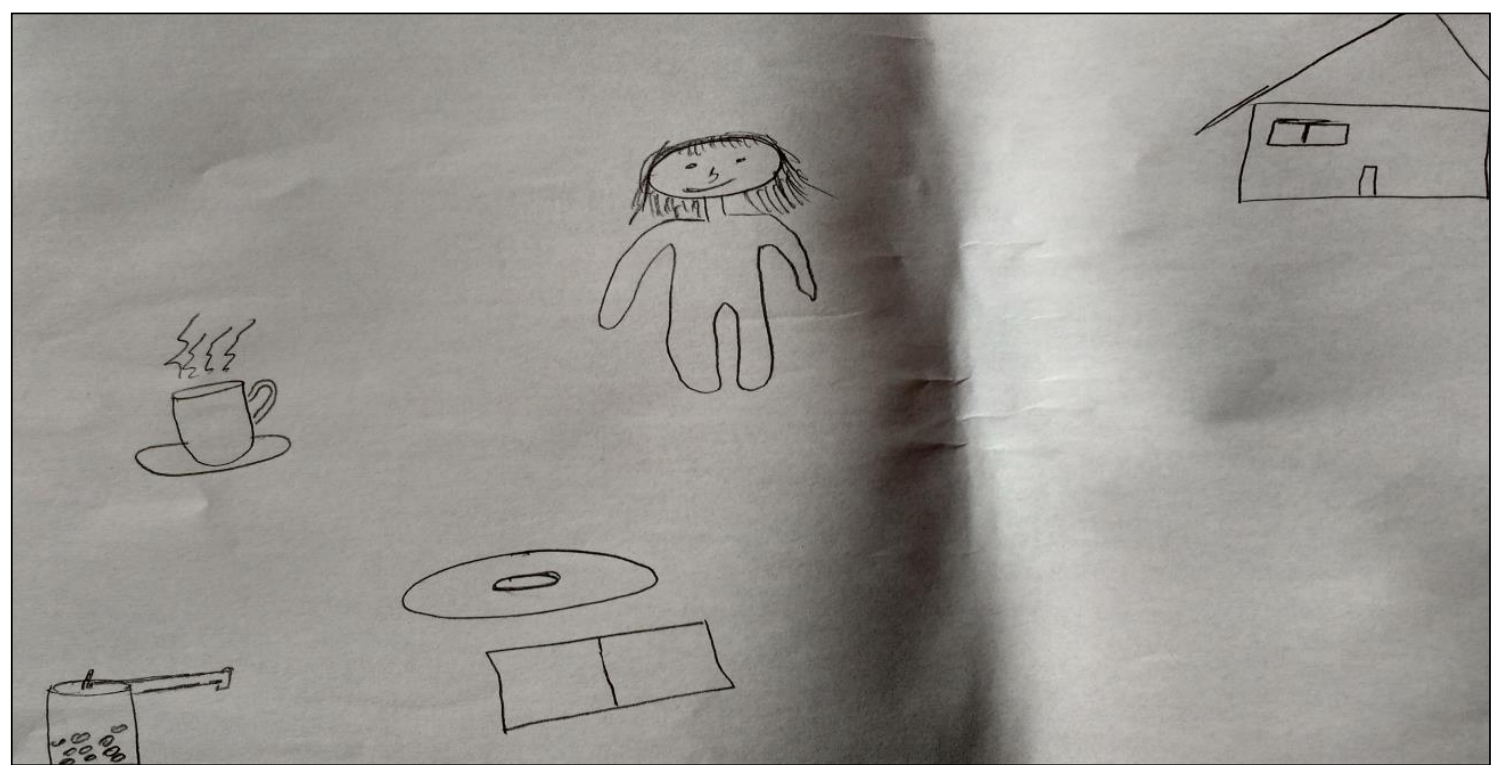

Figura 6: Registro do participante 5 (Dados da Pesquisa)

Observamos com os registros realizados pelos participantes a dificuldade que mesmo adultos tem em identificar as formas geométricas em objetos do nosso cotidiano, esse fato nos revela a necessidade de ampliação do conhecimento dos tópicos (KOT). Tal aspecto é citado por Lima e Carvalho (2010), que alertam para a necessidade de realização de atividades de visualização e percepção da Geometria no dia a dia. Essa percepção influência o planejamento de ações pedagógicas para o ensino de matemática que são consolidados no conhecimento do ensino de Matemática (KMT).

Após as produções, foi realizado um momento de reflexão sobre a atividade, no qual os professores expuseram como se sentiram ao realizar os desenhos. Alguns dos componentes do 
grupo relataram prazer e satisfação em realizar a atividade e outros consideram interessante fazer a relação do escrito (parlenda), como já referenciado pelo conhecimento das características da Matemática de aprendizagem (KFLM):

P3: É prazeroso utilizar o desenho e ver que a Matemática esta presente também na arte

P5: Gostei muito de perceber a relação que se pode estabelecer com textos escritos e a Matemática.

Os relatos permitem observar que as formações precisam desmistificar que a Matemática envolve somente as atividades do sistema de numeração e que é possível relacioná-la com diferentes áreas de conhecimento. Percebemos a necessidade de realização de mais formações envolvendo a Geometria, para que os professores se apropriem de especificidades do referido campo de estudo.

\section{Nossas considerações}

Este artigo pode mostrar uma possibilidade formativa interdisciplinar que permite a reflexão dos professores, alunos bolsistas e dos pesquisadores sobre a relação existente entre as diferentes áreas. Nos faz perceber que trabalhos que são desenvolvidos nessa vertente podem colaborar com a formação dos professores e, por consequência, irá contribuir significativamente com a aprendizagem dos alunos que irão relacionar o conhecimento escolar com a realidade.

Inferimos que o trabalho com parlendas para o ensino de Geometria pode ser o início de uma reflexão sobre propostas que permitam um ensino voltado para o entendimento, relação com a realidade e com outras áreas do conhecimento. Assim, realizar uma ação formativa nessa vertente é um dos caminhos possíveis para transformação.

Evidencia-se a necessidade de mais pesquisas que explorem essa temática envolvendo o uso de textos que se sabem de cor e as suas relações com o ensino de Matemática, tendo em vista que é um campo de estudo ainda de estudo inicial e que necessita ser explorado.

\section{Referências}

BJORKLUND, Camila. Aspects of challenged numbers in the game and in the interaction of toddlers. In: CONGRESS OF EUROPEAN RESEARCH IN MATHEMATICS EDUCATION, 10, 2017, Dublin. Proceeding of CERME 10. Dublin: ERME; Dublin City University, 2017, p. 1821-1828. 
BRASIL. Ministério da Educação. Secretaria de Educação Fundamental. Programa de Formação de Professores Alfabetizadores. Coletânea de textos do Módulo 2. Brasília: MEC/SEF, 2001.

CARRILLO-YAÑEZ, José; CLIMENT, Nuria; MONTES, Miguel; CONTRERAS, Luis Carlos; FLORES-MEDRANO, Eric; ESCUDERO-ÁVILA, Dinazar; VASCO, Diana; ROJAS, Nielka; FLORES, Pablo; AGUILAR-GONZÁLEZ, Álvaro; RIBEIRO, Miguel; MUÑOZ-CATALÁN, MaríaCinta. The mathematics teacher's specialised knowledge (MTSK) model. Research in Mathematics Education, v. 20, n. 3, p. 236-253, jul. 2018.

EMIRENE, Jessica. La na casa da vizinha. In: SANTOS, Fábio Vieira dos; RIBEIRO, Jackson da Silva Ribeiro; PESSOA, Karina Alessandra. A escola é nossa: Alfabetização Matemática, $1^{\circ}$ ano. São Paulo: Scipione, 2008, p. 20.

JELINEK, Karin Ritter; ADAM, Márcia Viviane dos Santos. Alfabetização Matemática entrelaçada à Literatura Infantil: um estudo da percepção de professores alfabetizadores. Tangram, Dourados, v. 3 , n. 1 , p. 46- 61 , mar. 2020.

KAMII, Constance. A criança e o número: implicações educacionais da Teoria de Piaget para a atuação junto a escolares de 4 a 6 anos. Tradução de Regina Alcântara de Assis. Campinas: Papirus, 1995.

LIMA, Paulo Figueiredo; CARVALHO, João Bosco Pitombeira Fernandes. Geometria. In: CARVALHO, João Bosco Pitombeira Fernandes (Coord.). Coleção Explorando o Ensino: Matemática - Ensino Fundamental. Brasília: MEC/SEB, 2010, p. 135-166.

LOZADA, Claudia de Oliveira; MORRONE, Wagner; ARAÚJO, Mauro Sérgio Teixeira de; LOZADA, Anneliese de Oliveira. O formalismo matemático na representação dos modelos em contextos interdisciplinares de modelagem matemática. Tangram, Dourados, v. 1, n. 2, p. 105-124, jun. 2018.

MASOLA, Wilson de Jesus; ALLEVATO, Norma Suely Gomes. Dificuldades de aprendizagem matemática: algumas reflexões. Educação Matemática Debate, Montes Claros, v. 3, n. 7, p. 5267, jan./abr. 2019.

SÃO PAULO (Estado). Secretaria de Estado da Educação. Ler e escrever: Guia de Planejamento e Orientações Didáticas. Professor Alfabetizador $-1^{0}$ ano. 4 ed. São Paulo: SEE, 2014.

SILVA, Rosemeire Jesus. Literatura infantil para o ensino de Matemática inclusiva. 2017. Trabalho de Conclusão de Curso (Pedagogia) - Faculdade de Educação. Universidade Federal de Grande Dourados.

WEISZ, Telma. O diálogo entre o ensino e a aprendizagem. São Paulo, Ática. 1999. 